(C) 2008 The Haworth Press. <http://www.haworthpress.com>. Final preprint version of article published in Slavic and East European Information Resources, Vol. 9, No. 1. Article copies available from The Haworth Document Delivery Service: 1-800-HAWORTH. Email address: docdelivery@haworthpress.com

\title{
DIGITAL ACCESS TO CULTURAL HERITAGE AND SCHOLARSHIP IN THE CZECH REPUBLIC
}

Brian Rosenblum*

\begin{abstract}
This article looks at selected digital library projects in the Czech Republic, with a focus on two main domains of activity: digital preservation of cultural heritage, and providing digital access to scholarship through institutional repositories. With regard to digitization of national cultural heritage, the Czech Republic, largely through the leadership of the National Library, has established itself as one of the most active countries in the region. With regard to providing access to Czech research and scholarship, although there is quite a bit of interest among research institutions and universities, institutional repositories are currently in the exploratory stage and have not yet been widely implemented. Copyright laws are repeatedly cited by Czech librarians as one obstacle to improving access to digital resources in both spheres of activity.
\end{abstract}

\footnotetext{
* Brian Rosenblum (MS in Information, University of Michigan) is currently Scholarly Digital Initiatives Librarian at the University of Kansas. Address correspondence to: Brian Rosenblum, Anschutz Library, 1301 Hoch Auditoria Drive, Lawrence, Kansas, 66049. (Email: brianlee@ku.edu). The author would like to thank the University of Kansas Library Research Fund, which provided support for travel and research for this article.
} 


\section{KEYWORDS}

Czech Republic, digital libraries, digitization, cultural heritage, institutional repositories, scholarly communication, open access, digital preservation

\section{INTRODUCTION}

The digital revolution of the last two decades has presented new and profound challenges to libraries, museums, archives and other institutions charged with preserving and providing access to our cultural and intellectual heritage. For Central and East European institutions the challenges have been even more complicated, for this digital revolution began in the aftermath of the fall of communism, in the midst of other major transformations in the social, political and economic spheres, when the very role of these institutions within society was changing. ${ }^{1}$ This article takes a look at the state of digital library activity in one Central European country, the Czech Republic, by surveying selected projects in two domains of activity: digital preservation of cultural heritage, and providing digital access to current scholarship through institutional repositories. Despite the challenges of the larger social and economic context, the Czech Republic has invested very heavily in the preservation of cultural heritage and, largely through the leadership of the National Library, has established itself as one of the most active countries in Europe. With regard to providing access to Czech research and scholarship, although there is quite a bit of interest among research institutions and universities, institutional repositories are currently in the exploratory stage and have not yet been widely implemented. Yet there are signs that that this is changing and repositories are beginning to be developed. 


\section{CULTURAL HERITAGE INITIATIVES}

\section{The National Library of the Czech Republic}

A 2006 study of national libraries across Western and Eastern Europe found a wide range of investment and expertise in the application of digital technologies to the preservation of cultural heritage, with no correlation between the amount of investment or expertise and whether an institution was in an EU member state, a new EU member state, or a non-EU member state. For example, national libraries in new EU-member states or non-EU states may have faster Internet connections than those in old EU-member states, and non-EU or new-EU states may have greater expertise or outperform EU-members in certain areas of activity. The study, conducted by The European Library (an initiative to coordinate policy and activity across national libraries and provide a portal to their collections), concluded that, with regard to national libraries, "there are no gaps between the EU-15 members, EEA states and the New Member States. In certain areas New Member States and Non-EU countries outperform the group of EU-15, EEA countries and Switzerland and may be considered the European centres of competence in certain areas of expertise." ${ }^{2}$

The National Library of the Czech Republic (NKP), located in Prague, scored particularly high in this study, ranking consistently among the top libraries in a variety of measurements, and having the highest amount of R\&D expenditures of all the national libraries surveyed. The NKP was one of the top five most active national libraries in international projects, and had one of the fastest internet connections in Europe. It was in the top five in the number and variety of technologies used, and was also fifth (behind Spain, France, the UK, and Austria) in number of 
objects digitized, with almost three million. In terms of digitization of manuscripts and early printed books, the Czech Republic, through the Manuscriptorium project (described below) has established itself as a European center of expertise. ${ }^{3}$

The NKP began exploring digitization and digital preservation very early on. In 1992, three years after the collapse of the communist government and in the midst of the split of Czechoslovakia into two countries, even as they were struggling with other pressing issues, such as poor storage conditions, incomplete cataloging of old volumes, and limited collections budgets ${ }^{4}$, the NKP became one of the original participants in UNESCO's Memory of the World program, an early effort to explore digitization as a means of cultural heritage preservation. Through the Memory of the World program, the NKP began to digitize manuscripts and old prints from their collection. (In 2005 the Czech National Library won the first UNESCO Memory of the World Jikji Prize for its contribution to the preservation of the world's cultural heritage. ${ }^{5}$ ) Since that time, the NKP's digital activities have continued to grow, and now center around three large national projects with the aim of preserving and providing access to different aspects of the cultural heritage of the Czech lands. These three projects are described briefly below.

Manuscriptorium $<$ http://www.manuscriptorium.com>. The longest running of the three projects, Manuscriptorium grew out of NKP's participation in the original UNESCO Memory of the World project. Now financed by the NKP and managed by a commercial firm, AiP Beroun, Manuscriptorium is both a union catalog of rare books and manuscripts, and a repository for digitized manuscripts, old printed books and other rare documents. Manuscriptorium includes not only items from the Czech National Library's collections, but has evolved into a collaborative 
program which enables other historical and cultural institutions in the Czech Republic and abroad to digitize and make available items from their collections. The Manuscriptorium database currently contains material from over 30 Czech cultural institutions (including libraries, archives, museums, and castles), as well as from several international partners from institutions in Poland, Hungary, Slovakia, Slovenia and Lithuania. In December 2006, the NKP announced that National Library of Turkey has joined the project and will add over 10,000 records relating to Turkish manuscripts, making it the largest foreign contributor to the project. Full-text and image content of Manuscriptorium currently includes more than 1,000 manuscripts and old printed books, or about 550,000 full-text pages, with a growth of about 105,000 to 120,000 digitized pages per year. ${ }^{6}$

In addition, Manuscriptorium provides a set of specially created tools for viewing the images and for creating bibliographic records of manuscripts for inclusion in the project. Metadata for the entire Manuscriptorium collection is available to the general public without restriction. Public access to the full data (including images and full text) is provided through individual and institutional licenses (the current institutional license is $200 \mathrm{USD} /$ year). Partner institutions receive free access to the entire content of the database. (Digital Scriptorium $<$ http://www.scriptorium.columbia.edu/>, a similar project administered at Columbia University and focusing on holdings in American libraries, has less content than Manuscriptorium, but makes images freely available online).

Kramerius <http://kramerius.nkp.cz>. Launched in 2000, Kramerius (named after Vaclav Matej Kramerius, an 18th-century publisher active in the Czech National Revival) follows a 
similar model to Manuscriptorium in allowing the NKP to partner with other institutions to digitize materials. But rather than old books and manuscripts, this project focuses on preserving and safeguarding more recent acid-paper materials, particularly newspapers, journals and brittle monographs from the 18th Century to the present. As of December 2006, Kramerius contains about 1.2 million pages of digitized material with an annual growth of about 400,000 pages. $^{7}$ As with Manuscriptorium, the metadata is available online to any user worldwide, but most images of the digitized documents are available only via computers on the premises of the National Library itself. The project website states that this is because most of the digital documents are "protected by copyright law," but it does not provide any further details. ${ }^{8}$

WebArchiv <http://www.webarchiv.cz/>. WebArchiv aims to provide a comprehensive, ongoing archive of the Czech World Wide Web (the .cz domain). A kind of "Wayback Machine" for the Czech Republic, WebArchiv was launched in 2000 and comprises several areas of activity, including developing the tools and methods for the ongoing collection and long-term preservation of web resources, integrating those records into the Czech National Bibliography, and providing access to those resources. The project is using both large-scale automated harvesting of the entire national web as well as a more labor-intensive, selective archiving of thematic and "event-based" collections, including Czech-related content residing outside the .cz domain. According to the project website, there are currently over 134 million documents harvested. ${ }^{9}$

WebArchiv is a collaborative initiative with two other institutions-- the Moravian Regional Library and the Institute for Computer Science at Masaryk University. Both are located in Brno 
and are providing support for IT issues. The WebArchiv partners have also begun working with institutions in other countries, including Slovakia, to help set up similar web archiving efforts.

As with Manuscriptorium and Kramerius, online access to WebArchiv content is currently limited, due to apparent legal restrictions in the Czech Republic. According to individuals involved with the project, the Czech Legal Deposit Act does not cover web pages, so web publishers are not required to provide the NKP with content they publish electronically, and current Czech copyright law prevents the partner institutions from making the archived data available to the public online without permission from the original publisher. ${ }^{10}$ The archived content is currently available using computers on the premises of the National Library and Moravian Library, but for those who can't visit the libraries in person, access is limited to content which is covered by agreements with original publishers. Given the vast and growing scope of the web, working out individual agreements with publishers of web pages is an inefficient, incomplete, labor intensive process which will not be sustainable in the long run. The law does allow, however, libraries to harvest and store online documents to preserve them and prevent them from disappearing forever. So to that extent, WebArchiv functions in part as a "dark archive," ensuring content is preserved, even though it may not always be accessible at the moment. While the focus now is on developing the harvesting and archiving technology to ensure the collection and preservation of web pages and electronic publications, in the future, the partner institutions hope that Czech intellectual property law will evolve to allow unfettered access to this material. ${ }^{11}$ 


\section{The Czech Digital Library}

In 2006, the NKP began to integrate these three initiatives, Manuscriptorium, Kramerius, and WebArchiv, into one administrative and technical infrastructure, to be known as the Czech Digital Library. Funded by the Ministry of Culture, any Czech library, museum, archive, or other institution can apply to have documents owned or produced by them included in the Czech Digital Library. If certain selection and technical criteria is met, they will be eligible to receive assistance from the Ministry of Culture for the digitization of those documents.

The first phase of implementation of the Czech Digital Library is scheduled for 2006-2010 and will focus on the integration of the three repositories, addressing a number of technical questions regarding standards, formats, storage technologies, and search and access technologies.

By bringing these three initiatives together, the Czech Digital Library will form a comprehensive program for capturing and preserving in digital formats a large range of the cultural heritage of the region, from manuscripts and early printed books, to modern newspapers, journals and other printed materials, to born-digital objects and web pages. ${ }^{12}$

\section{The Czech Digital Mathematics Library}

The National Library is not the only institution in the Czech Republic engaged in large digitization projects. The Czech Academy of Sciences (CAS), which oversees some 70 research institutes, is also very active in this arena. The main library of the CAS, located in Prague, began to be interested in digital preservation after the Prague floods in 2002, which, in addition to devastating many buildings and streets in Prague, damaged large amounts of materials in 
libraries throughout the country. ${ }^{13}$ In the aftermath of the floods, the CAS built a digitization center and began the digitization of materials from 1895 on, focusing in particular on old journals from their collections. Using Czech software built specifically for this purpose, they have the capacity to digitize as much as 50,000 pages per month.

Some of this capacity is being used to build the Czech Digital Mathematics Library (CDML). Scheduled for completion in 2009, the CDML will consist of "the relevant mathematical literature which has been published throughout history in the Czech lands." ${ }^{14}$ The CDML will contain an estimated 250,000 pages when completed, and will include professional journals of international stature published by Czech institutions, as well as monographs, textbooks, dissertations, research reports, and conference proceedings published by Czech universities and research institutes. (When completed, the content will also be incorporated into the World Digital Mathematics Library, an initiative of the International Mathematics Union to coordinate the digitization of math literature worldwide.)

Like WebArchiv, the CDML is a collaborative project with contributions from several institutional partners. The Mathematical Institute of the Academy of Sciences and the Faculty of Mathematics and Physics at Charles University in Prague are providing subject expertise and project coordination, while the Library of the Academy of Sciences, the Faculty of Computer Science at Masaryk University in Brno, and the Institute of Computer Science at Masaryk University (also involved in the WebArchiv project) are providing the digitization, search functionality, and various other technical components. ${ }^{15}$ 
As with the NKP initiatives described above, project managers indicated that copyright issues may limit the extent of access to the digitized content, and said they are currently in negotiations with Czech publishers to work out the terms of online access. ${ }^{16}$

\section{SCHOLARLY COMMUNICATION INITIATIVES}

\section{Institutional Repositories}

The projects discussed above focus on content that can be considered to be part of the cultural heritage of the region. Digitization can also play a role in providing access to and preservation of current scholarship, which is an increasing need for universities and research institutions.

A 1999 report on scholarly communication needs in the Czech Republic noted several challenges in the environment at that time, 10 years after the collapse of communism. Some of the challenges identified in the report include:

- a shortage in access to contemporary academic books and journals

- need for improved access to grey literature produced abroad

- need for improved access to Czech grey literature by foreign scholars interested in the Czech Republic

- access to conference proceedings $^{17}$

Such challenges are not unique to the Czech Republic. They are, in fact, representative of the socalled "scholarly communication crisis" that is impacting academic and research institutions 
worldwide, and that is the result of, among other things, skyrocketing prices of scholarly journal subscriptions, the explosion in the amount of new scholarly publications, and a restrictive intellectual property environment. Such concerns have led many libraries to explore new initiatives to influence and create change in the scholarly communication system. One strategy in particular that is gaining widespread momentum, especially in the U.S., Western Europe, and Australia, is the implementation of institutional repositories.

Institutional Repositories (IRs) are a set of services to manage and disseminate the scholarly knowledge created by faculty, researchers, or students at an institution. Although IRs are not a preservation strategy in and of themselves, they put digital scholarship into a managed process which can make the complex task of preservation easier. In addition, IRs play an important role in the Open Access (OA) movement, which seeks to make scholarly material freely available to as large a worldwide audience as possible by making the material openly available on the Internet. By providing unobstructed access to scholarship, institutions can maximize the visibility and potential impact of the work of their faculty. ${ }^{18}$

\section{Institutional Repository Deployment Central and Eastern Europe}

Although still in the early stages of development, IRs have become widely deployed at research institutions in the U.S. and Western Europe. A recent survey of IR deployment in the U.S. and Western Europe concluded: "it is clear, at least among the nations surveyed, that institutional repositories are becoming well established as campus infrastructure components. They are broadly deployed in many of the countries surveyed, and essentially universally available in a few already." ${ }^{19}$ 
In Central and Eastern Europe, repository deployment has proceeded more slowly. Although the 2002 Budapest Open Access Initiatives (http://www.soros.org/openaccess/) (BOAI), which strongly encourages open access to research and the use of institutional repositories, has a high profile in the region, this has apparently not yet led to the widespread implementation of IRs. A few brief statistics will illustrate this point.

The University of Michigan's OAIster search engine (http://oaister.umdl.umich.edu) harvests metadata from open access repositories, journals, and digital library collections worldwide. Launched in 2002, OAIster now contains over 10 million records of (mostly) freely available material residing in over 700 repositories in 44 countries. Table 1 provides a breakdown by country of the number of items indexed by OAIster, as of October 6, 2006. Approximately half of the 10 million records in OAIster reside in U.S. repositories. Only $2 \%$ of the total of repositories harvested by OAIster are in Eastern Europe or Slavic-language countries, and together they contain only $0.5 \%$ of the total content in OAIster. Remove Poland and the figures decrease to $1 \%$ of the repositories and $0.1 \%$ of the total content.

[INSERT Table1.doc]

Figures from the Registry of Open Access Repositories (ROAR) (http://roar.eprints.org/) are similar (see Table 2). Out of the 754 repositories from 51 countries listed in ROAR as of October 2006, 4 repositories are in Russia, 4 in Hungary, and 1 each in Croatia, Poland, Slovenia and Ukraine. Together this represents $1.5 \%$ of the total number of repositories listed. No other East 
European or Slavic speaking nation is represented in the registry. By contrast, the top ten countries (led by the United States with 200 repositories, the U.K. with 79, and Germany with 68 ), have $75 \%$ of the listed repositories.

[INSERT Table2.doc]

It is important to note that there are some important limitations to these figures and they may not fully represent the use of repositories in the region. ${ }^{20}$ Nevertheless, they do give us a general indication of where the main development of repositories has taken place to date, and they give a sense of the low Eastern European presence in two of the more well-known and established IR tools. This suggests that institutions in East European countries have not yet fully developed the repository infrastructure that can help preserve their own research output, make it more accessible worldwide, and increase the visibility and impact of their own scholars. This is not necessarily a disadvantage yet, although in the long run it could be. IRs are still a relatively new technology and even the early adopters of this technology are still exploring how best to deploy IRs and fill them with content. Eastern European institutions can thus pay attention to and take advantage of the lessons currently being learned by early IR adapters elsewhere.

\section{Institutional Repositories in the Czech Republic}

There are no Czech repositories currently listed in OAIster or ROAR, and no one I spoke with during a visit to the Czech Republic in the summer 2006 was aware of any fully-implemented, open access institutional repositories. There was, however, quite a lot of interest in such repositories and there are many institutions starting to explore how to implement them. 
For example, the Institute for Computer Science (ICS) at Masaryk University (MUNI) in Brno has been very active in researching and testing IR technology. They are well aware of current trends and developments with regard to institutional repositories in Western Europe and the U.S., and, anticipating the possibility of a need arising at MUNI, they have been laying the groundwork for the eventual implementation of an IR. For ICS (which is a partner in both the WebArchiv and Czech Digital Mathematics Library projects) it is not the technical challenges which are delaying the development of an IR, but rather an array of other more intangible factors in the wider academic landscape, such as support from high-level administrators, pressure from faculty, legal mandates for the deposit of research in repositories, and the existence of friendlier copyright laws, that do not yet seem to be in place, and which are necessary to move repository development forward. ICS doesn't see it as their role to be the main advocate for the development of IRs, but rather to be prepared to provide that service when the need arises.

More investigation is needed to truly understand the scholarly communication environment in the Czech Republic, but there are signs that the environment is starting to change and put more pressure on institutions to implement repositories to provide access to their research output. Two brief examples will illustrate this. In the first example, recent legislation has forced universities to find ways to provide access to the theses and dissertations written by their students. In the second example, a research institute's involvement with an international consortium is driving the implementation of an IR. 


\section{Theses and Dissertations and Open Access}

In the Czech Republic, attention to open access (OA) to scholarship has so far largely focused on theses and dissertations. In 2005, the Czech legislature passed a law requiring public universities to provide free, electronic, public access to theses and dissertations of students who have been awarded degrees at those institutions. ${ }^{21}$ There were several motivations behind the enactment of this new law. Until this time, Czech universities have had no responsibilities or obligations concerning making theses and dissertations available. Requiring public access to theses and dissertations will provide more quality control and accountability on the part of universities receiving public funds. In addition, making such research available to the public will increase public debate and knowledge, and therefore have a positive social impact that can help justify the public funds these institutions receive. The law applies only to theses and dissertations awarded January 1, 2006 or later.

Because of potential conflict with the rights of authors of theses and dissertations to decide how their work would be made available, Czech copyright law was also modified. Now, as a condition of submitting their thesis or dissertation, students agree to have it made publicly available in electronic form.

There remains some confusion and loopholes in the law, however, with the result that there is some inconsistency in how different universities are interpreting and implementing access to their thesis and dissertations. While universities are required to provide public, electronic access to this material, it is left up to them to each individual institution to determine the mechanisms and process by which to provide this access. Most universities are using some kind of local 
system already in place at their institution. In some cases, as at Masaryk University in Brno, or the University of Ostrava, this data is made available through a public system which allows robust searching by keywords, authors, English and Czech language abstracts, faculty advisor, year of defense, and other terms. Masaryk University is also working on providing full-text searching of theses and dissertations. At other universities, access is made through the existing library catalog, which may limit the search terms to author and title and subject, and which requires users to search across the entire holdings the library at the same time.

Another issue has been definition of "public access." At some institutions, an electronic database of dissertations is available, but only on the premises of the institution itself, not online via the Internet. This seems to run counter to the spirit of the law, although in some cases it may stem from current technical limitations at those universities.

There is inconsistency in the range of content available as well. The legislation applies only to theses and dissertations submitted January 1, 2006 or later, and some universities limit access to content which falls into that time frame. Other institutions however, are making older material available. Despite such inconsistency and certain loopholes, this legislation is recognized by many as a positive first step of making one sector of Czech grey literature more available.

\section{CERGE-EI and Economists Online}

In 1993, the Center for Economic Research and Graduate Education (a unit of Charles University in Prague) and the Economics Institute (a part of the Czech Academy of Sciences) established a joint program, known as CERGE-EI. CERGE-EI provides an American-style Ph.D. program in 
economics and conducts economic research, with a particular emphasis on the transition to free markets and European integration. All courses are taught in English, and the Ph.D. degree from CERGE-EI is fully recognized in the United States. The CERGE-EI Library was established in 1992 and is one of the best libraries in the region for access to economics resources. The library also has a strong history of providing public access to it's resources, having been open to the public since 1994.

In 2006 CERGE-EI joined the Nereus consortium (a network of European economics research institutes) and became a participant in the Economists Online project, which provides a portal to the research output of participating institutes available online. As part of their participation in Economists Online, the CERGE-EI will place about $80 \%$ of the published work produced by CERGE-EI faculty into a repository to be made freely accessible online. At the time this article was written, CERGE-EI had not yet developed their IR and was looking into various optionsincluding maintaining it themselves, or finding for a commercial vendor to host it. Neither of CERGE-EI's sponsoring institutions, Charles University or the Academy of Sciences, currently has an open-access institutional repository infrastructure that would meet CERGE-EIs needs.

The Czech Academy of Science would seem to be a natural institution for implementing an IR-the 70 or so institutes of the CAS produce a wide range of research and scholarly publications. However, the research institutes that comprise the CAS span a wide range of scholarly disciplines, vary widely in size and scope, and, as in the case of CERGE-EI, may have unique needs that require them to form their own external partnerships based on their own individual needs. Implementing a repository that meets the needs of faculty at a single institution is a 
challenge in itself. Trying to coordinate 70 semi-autonomous research units is even more complex.

\section{CONCLUSIONS}

Christine Borgman has noted that libraries in Central and Eastern Europe have historically been "oriented more towards preservation of cultural heritage than access to information."22 The activities of Czech institutions in the digital realm seem to bear this out. The Czech Republic has invested heavily in cultural heritage preservation initiatives and has established itself as a European leader in digitization and web archiving activities. The national digitization projects have been successful in part because of the strong leadership that the National Library has shown, the high-level support they have received from the Ministry of Culture, and the collaborative nature of the projects.

Czech universities and research institutions have been somewhat slower to implement institutional repositories and focus on providing access to Czech research, scholarship and grey literature. Similar levels of commitment and collaboration to that seen in the national cultural heritage projects may help lay the groundwork for a broad repository to help preserve and distribute current Czech research and scholarship. As demonstrated by the inconsistent levels of access currently provided by universities to their theses and dissertations, there may be a benefit to establishing a repository at a multi-institutional, or even national, level, rather than having each individual institution duplicating effort and establishing and maintaining its own system. 
On the other hand, Czech universities may not have as strong a history of cooperation as Czech libraries and cultural heritage institutions, and may tend to view the implementation of repositories in a more competitive light. Nevertheless, the fact institutions are laying the groundwork for repository implementation (looking at technical requirements, researching different systems options) suggests that pressures to move in this direction are starting to build, and that we may be on the cusp of seeing a broad implementation of IRs at universities and research institutions in the Czech Republic.

Indeed, the extent of repository activity in the Czech Republic could develop very fast. Internationally, repository and open access activities are gaining momentum: funding agencies are beginning to mandate that the results of research they fund be deposited into open access repositories, and concerns about capturing, organizing, and preserving born-digital items and data in a variety of file formats are driving widespread repository development. As those influences make their way into the Czech scholarly environment, research institutions and universities are likely to find the demand for IRs growing. 


\section{Notes}

${ }^{1}$ For more information on the history of Czech libraries and their changing role over time, see Rebecca Rhodes, "Libraries, Librarianship and Library Education in the Czech Republic" (Master's paper for the M.S. in L.S. degree, University of North Carolina, 2002).

${ }^{2}$ Zinaida Manžuch and Adolf Knoll, "Research Activities of the European National Libraries in the Domain of Cultural heritage and ICT," (TEL-ME-MOR, 2006), 4.

http://www.telmemor.net/docs/D1.3_research_activities_report.pdf.

${ }^{3}$ Manžuch and Knoll, "Research Activities of the European National Libraries," 15-37.

${ }^{4}$ Adolf Knoll, "Universal availability of publications problems in Czechoslovakia," Fontes Artis Musicae 39 (1992): 255-8.

5 "Czech National Library to receive UNESCO/Jikji Memory of the World Prize," UNESCO

WEBWORLD, September 1, 2005, Communication and Information Sector News, http://portal.unesco.org/ci/en/ev.php-

URL_ID=19783\&URL_DO=DO_TOPIC\&URL_SECTION=201.html (accessed March 27, 2007).

${ }^{6}$ TEL-ME-MOR, “Digital Library-Related Initiatives in Europe,” The European Library, http://www.telmemor.net/diglib.php (accessed March 27, 2007). 
${ }^{7}$ TEL-ME-MOR, "Digital Library-Related Initiatives in Europe.”

${ }^{8}$ During interviews and conversations I had with Czech librarians working on this and other projects, they repeatedly cited Czech copyright laws as a major obstacle to making digital content available to a wider audience. This applied to the cultural heritage projects discussed here, as well as to efforts to place scholarship into institutional repositories, discussed later in this article. I found little documentation available in English about Czech copyright law, but the following websites (in English and Czech) represent places to get further information:

- "Autorské právo," Ministry of Culture of the Czech Republic $<$ http://www.mkcr.cz/autorske-pravo/default.htm>

- "Autorské právo a knihovny (Author's rights and libraries)," National Library of the Czech Republic, <http:/www.nkp.cz/o_knihovnach/AutZak/Dop.htm>

- "Czech Library and Information Science Portal," National Library of the Czech Republic (see links under the section labeled "Legislation") <http://knihovnam.nkp.cz/english/> - "Odměna autorům za půjčování jejich děl v knihovnách [The reward to authors for the lending of their work in libraries]" Ikaros: Elektronický časopis o informační společnosti, Roč. 9, č. 6 (2005), <http://www.ikaros.cz/node/1973>

Also see the article by Vera Jurmanová Volemanová cited in footnote 21 below. In addition, the American Association for the Advancement of Slavic Studies maintains, through its Bibliography \& Documentation Subcommittee on Copyright Issues, a list of resources and links related to copyright in the wider region. See: < $\underline{\text { http://intranet.library.arizona.edu/users/brewerm/copyright/awareness.html. }}$. 
9 "WebArchiv - Archive of the Czech Web," http://en.webarchiv.cz/ (accessed March 27, 2007).

10 "WebArchiv - Archive of the Czech Web," http://en.webarchiv.cz/ (accessed March 27, 2007) and personal conversations with project personnel.

11 “WebArchiv - Archive of the Czech Web,” http://en.webarchiv.cz/ (accessed March 27, 2007).

${ }^{12}$ Bohdana Stoklasova, "Czech Digital Library" (paper presented at the 1st Colloquium of Library Information Employees of the V4+ Countries, Bystrica, Slovakia, May 11-13, 2006), http://www.svkbb.sk/colloquium/zbornik/obsah.htm.

${ }^{13}$ For more on the Czech library response to the floods, see Emily Ray, "The Prague Library Floods of 2002: Crisis and Experimentation," Libraries \& the Cultural Record 41, no. 3 (2006): 381-391.

${ }^{14}$ Jirí Rákosník, "DML-CZ: Czech Digital Mathematics Library," ERCIM News 66 (2006), http://www.ercim.org/publication/Ercim_News/enw66/rakosnik.html.

${ }^{15}$ Rákosník, "DML-CZ: Czech Digital Mathematics Library.”

${ }^{16}$ Interviews and conversations with project personnel. 
${ }^{17}$ Zdenka Mansfeldová, "Report on Scholarly Communication Needs in the Czech Republic," unpublished report for the Social Sciences Research Council, Working Group on Dissemination (1999).

${ }^{18}$ For one overview (among many others) of IRs and the issues related to their implementation, see Mark Ware, "Pathfinder research on web-based repositories: Final report," Bristol, UK, Publisher and Library/Learning Systems (PALS), http://www.palsgroup.org.uk/palsweb/palsweb.nsf/79b0d164e01a6cb880256ae0004a0e34/8c43c e800a9c67cd80256e370051e88a/\$FILE/PALS\%20report\%20on\%20Institutional\%20Repositorie s.pdf.

${ }^{19}$ Gerard van Westrienen and Clifford A. Lynch, "Academic Institutional Repositories: Deployment Status in 13 Nations as of Mid 2005)," D-Lib Magazine 11, no. 9 (September 2005), http://www.dlib.org//dlib/september05/westrienen/09westrienen.html.

${ }^{20}$ There are a number of caveats to note about with these figures. To begin with, they represent a mostly self-selected group of repositories or publications that have chosen to register with OAIster or ROAR. In OAIster, many of the "sources" represent different types of collections, so it is not always clear what types of items one is comparing. For instance, the sole source from Bulgaria is not an institutional repository but an OA journal, Bulgarian Rusistika, published by the Society of Philologists of Bulgaria. Assessing repository development by number of items is problematic because, as Clifford Lynch has pointed out, "no two institutions are counting the 
same things.... The diversity in both the definition of what constitutes an "object" and in the nature of the objects being stored (massive videos or groups of datasets as opposed to individual articles or images) makes repository size very hard to interpret." In addition, these figures do not take into account the relative size of the countries in terms of number of research institutions and faculty, nor do they take into account the fact that East European scholars in some fields already make use of subject-based repositories located in the United States or Western Europe.

${ }^{21}$ The information in this and the following paragraphs, including the discussion of the new legislation and the responses of Czech universities was obtained from Vera Jurmanová Volemanová, "Fulltextové databáze VŠKP (vysokoškolských kvalifikacních prací) volný prístup k cennému zdroji odborných informací [Fulltext Databases of Theses and Dissertations Free Access to Valuable Source of Specialized Information]," (paper presented at Inforum 2006, May 23-25, 2006, Prague, Czech Republic), http://www.inforum.cz/inforum2006/pdf/Jurmanova_Volemanova_Vera.pdf.

${ }^{22}$ Christine Borgman, From Gutenberg to the Global Information Infrastructure: Access to Information in the Networked World (Cambridge, MA: MIT Press, 2000), 243. 